\title{
As Travestis no Programa Saúde da Família da
}

\section{Lapa}

\section{Transvestites in the Family Health Program of Lapa}

\section{Valéria Ferreira Romano}

Médica e Doutora em Saúde Coletiva pelo Instituto de Medicina Social - Universidade do Estado do Rio de Janeiro. Professora Ad-

junta III - docente do Mestrado Profissional em Saúde da Família UNESA/RJ.

Endereço: Rua Assis Brasil, 70/1002, Copacabana, CEP 22030-010, Rio de Janeiro, RJ, Brasil.

E-mail: valromano®uol.com.br

\section{Resumo}

Este texto apresenta o relato de experiência sobre o acolhimento das travestis no Programa Saúde da Família Lapa (PSF-Lapa), uma unidade de saúde de atenção básica, situada no bairro da Lapa, centro do Município do Rio de Janeiro. O PSF-Lapa é parte integrante do curso de Medicina da Universidade Estácio de Sá, em parceria com a Secretaria Municipal de Saúde do Rio de Janeiro, servindo de cenário de ensino-aprendizagem dos alunos do curso de Medicina e de outras áreas da saúde da universidade. Apoiada no fato de que o acesso das travestis aos serviços de saúde pública tem sido pautado pelo preconceito tanto de profissionais quanto de usuários, tece considerações sobre a humanização da relação aluno - profissionais de saúde - usuários, no que concerne ao direito à saúde. Relata as estratégias utilizadas para promover o acolhimento das travestis pela equipe de saúde, pelos usuários e alunos envolvidos, a partir da lógica do respeito à diversidade.

Palavras-chave: Programa de Saúde da Família; Humanização da atenção; Travestis. 


\section{Abstract}

This text reports the experience of sheltering transvestites in the Family Health Program of Lapa (PSFLapa), a health center that provides basic care, situated in the neighborhood of Lapa, in the downtown area of the city of Rio de Janeiro. PSF-Lapa is an integral part of the Medicine program of UNESA (Estácio de Sá University), in partnership with the Municipal Health Department of Rio de Janeiro. It serves as a teaching-learning scenario for students of the Medicine program and of other health areas of the university. Supported by the fact that the transvestites' access to public health services has been characterized by prejudice on the part of professionals and users, this paper discusses the humanization of the relationship student-health professionals-users, concerning the right to health. It reports the strategies used to promote the sheltering of the transvestites by the health team, users and students involved, based on the logic of respect for diversity.

Keywords: Family Health Program; Humanization of care; Transvestites.

\section{No Contexto: as travestis}

Na diferenciação entre travestis, transexuais e homossexualidade temos que travestis são pessoas que fazem uso de vestimenta do sexo oposto para satisfazer experiência de pertencer ao sexo oposto; e transexuais são pessoas que não aceitam o sexo que ostentam anatomicamente (Brasil, 2004).

Já a homossexualidade é definida como atração afetiva e sexual por pessoa do mesmo sexo. Depende da orientação sexual que é considerada como atração afetiva e/ou sexual de uma pessoa pela outra (Brasil, 2004). Ainda em relação à homossexualidade, é importante considerar que esta foi retirada da relação de doenças pelo Conselho Federal de Medicina desde 1985; e o Conselho Federal de Psicologia estabelece, desde 1999, que nenhum profissional pode exercer ação que favoreça a patologização de comportamentos ou práticas homoeróticas (CFP, 2006). No entanto, a Classificação Internacional de Doenças (CID-10) considera as travestis e transexuais como possuidoras de um transtorno da identidade sexual, ou seja, são consideradas como pessoas portadoras de uma doença, merecedoras, portanto, de um tratamento que objetive uma cura (Centro Colaborador da OMS para a Classificação de Doenças, 1993).

No convívio com as travestis, percebe-se ser este um grupo social estigmatizado (Goffmann, 1975) e, portanto, pouco compreendido pelas pessoas em geral e pelos profissionais de saúde em particular, gerando distorções na eqüidade, um dos princípios básicos do SUS.

Assim, este artigo relata como, em um serviço de atenção básica de um grande centro urbano, que pretende ser a porta de entrada para o sistema de saúde, tem sido realizado um trabalho de acolhimento das travestis, moradoras da área adscrita.

\section{O Programa Saúde da Família da}

\section{Lapa}

A Política Nacional de Atenção Básica (PNAB), aprovada e publicada em 2006 (Brasil, 2006), fundamentada nos princípios assistenciais e organizativos do SUS: universalidade, integralidade e eqüidade, em um contexto de descentralização e controle social da gestão; redefine, entre outras questões, as características do 
processo de trabalho a partir das especificidades da estratégia Saúde da Família.

Considera, dessa forma, a Saúde da Família como estratégia prioritária da Atenção Básica no sentido de sua potencialidade em se organizar de acordo com os preceitos do SUS.

Os gestores do SUS, representados em suas três esferas, pactuaram também em 2006, na Comissão Intergestores Tripartite (CIT), o "Pacto pela Saúde", a partir da determinação de três dimensões: Pacto pela Vida, Pacto em Defesa do SUS e Pacto de Gestão (Brasil, 2006).

O Pacto pela Vida define como prioridade "consolidar e qualificar a estratégia Saúde da Família como modelo de Atenção Básica e centro ordenador das redes de atenção à saúde no Sistema Único de Saúde (SUS)" (Brasil, 2006).

Dessa maneira, podemos afirmar que a estratégia Saúde da Família representa, hoje, a voz e o lugar oficiais da Atenção Básica no Brasil, colocando em discussão seu processo de trabalho.

Acreditando que a oferta de ações, a sua utilização e o contato por ações programáticas têm a tendência de serem mais adequados na Saúde da Família do que em uma Unidade Básica de Saúde tradicional (Facchini e col., 2007); reforçamos a importância da participação das equipes no planejamento e na avaliação de ações voltadas à população.

Segundo o Ministério da Saúde, na metodologia de trabalho do Programa, ou como tem sido mais recentemente chamado, estratégia Saúde da Família, a equipe de saúde realiza sistematicamente visitas domiciliares, atendimento ambulatorial, atividades de educação em saúde e reuniões comunitárias em um território delimitado de abrangência.

A lógica do trabalho valoriza o doente e não a doença; a família e não apenas o indivíduo; a promoção da saúde e não tão somente ações curativas ou preventivas; o vínculo, a integralidade e a continuidade da atenção a partir das necessidades de saúde das pessoas.

Implantado em 2001, a partir de um convênio firmado entre a Secretaria Municipal de Saúde do Rio de Janeiro e a Universidade Estácio de Sá (UNESA), o Programa Saúde da Família Lapa (PSF-Lapa) formatou, dentro de seu Curso de Medicina, um eixo curricular em que a Saúde da Família teria um lugar de destaque. Na lógica da formação médica a partir da diversifica- ção de cenários de prática, ocupou um espaço de interação direta dos alunos com a comunidade.

O PSF-Lapa, situado no centro da cidade do Rio de Janeiro, na Lapa, considerada uma região de boemia, é freqüentado obrigatoriamente por todos os alunos do Curso de Medicina que estejam cursando o $6^{\circ}, 9^{\circ}, 10^{\circ}$, $11^{\circ}$ e opcionalmente o $12^{\circ}$ períodos. Os alunos do $10^{\circ}$, $11^{\circ}$ e $12^{\circ}$ períodos são considerados internos de Medicina, perfazendo um quantitativo atual de 107 alunos por semana, distribuídos por uma carga horária semanal de 4 horas/cada (segundo semestre de 2007).

Durante o $6^{\circ}$ período, os alunos têm uma visão da população adscrita quando realizam pequenos diagnósticos locais de saúde. Do $9^{\circ}$ ao $12^{\circ}$ períodos, recebem 10 famílias cada, tendo então a responsabilidade de acompanhá-las, totalizando assim até dois anos de seguimento do mesmo grupo familiar. Ações coletivas de promoção e prevenção, como grupos de caminhada, coral, corte e colagem, alimentação saudável, idosos e travestis, são realizados pelos alunos sistematicamente, sob supervisão docente.

Desta forma, o vínculo, a humanização da relação, o foco no cuidado, a aproximação com a realidade social das famílias adscritas, além do manejo com o sistema de saúde em geral, estariam na pauta de prioridades destes alunos que vivenciam a relação médicopaciente por meio de atividades ambulatoriais, visitas domiciliares e atividades de educação em saúde.

O perfil da população adscrita ao PSF-Lapa é principalmente constituído por adultos -jovens e idosos, com ensino fundamental incompleto, renda familiar entre 2 a 5 salários mínimos, em sua maioria trabalhadores informais, prevalecendo o gênero feminino e com $100 \%$ de saneamento básico e coleta de lixo. Moram no Centro da cidade do Rio de Janeiro, no bairro da Lapa, principalmente em prédios com apartamentos de até 2 cômodos, geralmente alugados, alguns invadidos, ou vivem em grandes cortiços onde se acumulam até 20 quartos, cada um deles ocupado por uma família diferente que, em casarões seculares e mal conservados, têm banheiro coletivo, não possuem cozinha ou área livre comum.

O quantitativo da população adscrita ao PSF-Lapa é de cerca de 1200 famílias ou 4300 pessoas, distribuídas por 6 microáreas, cada uma sob a responsabilidade de uma médica. Dessa forma, a equipe mínima do PSF-Lapa é composta por: 6 Médicas, 6 Agentes Comu- 
nitárias de Saúde, 2 Enfermeiras, 2 Auxiliares de Enfermagem e 1 Recepcionista.

Na equipe ampliada trabalham conjuntamente: 1 Odontólogo, 2 Enfermeiras, 1 Fonoaudióloga, 2 Fisioterapeutas e 1 Nutricionista. Todos os profissionais de nível superior acumulam dupla função: a da docência e a da assistência.

\section{Características das Travestis do PSF-Lapa}

Há uma prevalência de cerca de 90\% na faixa etária entre 20 e 30 anos, sendo que $80 \%$ não é natural do Rio de Janeiro, com predominância da região Nordeste (cidades de pequeno porte populacional) e Sudeste (interior de Minas Gerais e Espírito Santo, principalmente). Possuindo baixa escolaridade (100\% possui ensino fundamental incompleto) e sem qualificação profissional, trabalham como profissionais do sexo nas ruas do próprio bairro em que residem.

As principais patologias encontradas são doenças dermatológicas como: escabiose, herpes simples, herpes zoster, pitiríase versicolor, tinea cruris, tinea corporis, psoríase e doenças sexualmente transmissíveis com predominância de: condilomas, sífilis e HIV. Há uma tendência à depressão e estados de ansiedade com uso abusivo de medicação psicotrópica, álcool e drogas em geral, tanto lícitas quanto ilícitas. 0 uso abusivo de álcool merece destaque, pois é o mais utilizado pelas travestis. Elas iniciam seu consumo antes mesmo de saírem de casa, enquanto se arrumam, no início da noite. Utilizam principalmente bebidas destiladas, a exemplo da cachaça e fermentadas, como a cerveja, normalmente em grande quantidade. Enquanto estão nas ruas para trabalhar, continuam seu consumo, que é aumentado quando estão junto aos clientes. Com bastante freqüência amanhecem o dia embriagadas.

Possuem muitos e sérios problemas de saúde bucal, demandando encaminhamento para tratamento imediato.

Mantém uma dieta hipercalórica e pouco balanceada, com pequeno consumo de frutas e fibras, além de ingerirem pouca quantidade de água, preferindo bebidas industrializadas, como refrigerantes. Não fazem uso de água filtrada, utilizando-se de água da torneira para consumo em geral.

Possuem enorme preocupação com a estética, o que as estimula a realizar, freqüentemente, procedimentos a laser para eliminação de pêlos na face, cirurgias para colocação de silicone nos seios, quadris e pernas, além de correções de angulação e espessura de nariz. Muitas não podem pagar à medicina privada tais cirurgias e procedimentos, utilizando-se assim de silicone líquido industrial injetado por elas mesmas, o que ocasiona infecções e tromboses principalmente em membros inferiores, causa de internação hospitalar. Na busca de maior feminilização, a exemplo de aumento dos seios, mudanças no timbre da voz, presença de pele mais fina; a ingestão de hormônios femininos é abusiva, tendo como principal conseqüência distúrbios hepáticos.

Um dos maiores problemas a serem enfrentados na atenção médica com as travestis é o da descontinuidade e, principalmente, abandono de tratamentos, refletindo em um alto índice de absenteísmo. Mesmo diante de doenças crônicas ou de doenças graves que requerem cuidados contínuos, como é o caso da Aids, as desistências são muito freqüentes.

\section{No Encontro com as Travestis}

Residem no território de abrangência do PSF-Lapa cerca de 30 travestis, que vivem, em sua maioria, nos casarões mal cuidados e empobrecidos, sobreviventes de uma situação social de desigualdade absoluta.

Como médica da equipe, iniciei um trabalho, em 2001, com esse grupo de travestis aonde, semanalmente, em conjunto com a Agente Comunitária e os alunos do Curso de Medicina e/ou outros alunos da área da saúde, realizamos visitas domiciliares com o objetivo de distribuição de camisinha e gel, troca de idéias e saberes na lógica da interação, a partir de uma abordagem dialogal da promoção de saúde, além da realização de consultas para fins de diagnóstico, tratamento, recuperação ou reabilitação da saúde.

Dentro de um enfoque descritivo, tomando de empréstimo da pesquisa social a técnica etnográfica de se relacionar com o estudo de grupos sociais particulares, destaco um recorte da vivência com o grupo de travestis, relatado a seguir, a título de ilustração.

Assim, subindo as inacabáveis escadas iniciadas logo após a abertura da única porta de acesso à rua, pautava cada passo em meio à escuridão que se instalara. Lá em cima nos aguardavam uma travesti com 
seus cabelos presos, saia justa e o rosto mal refeito do sono despertado. Já eram 15 h e sabia que começavam a acordar da longa jornada noturna de trabalho na rua.

- Boa tarde, doutora, tudo bem?

- Oi, menina, como está?

Em companhia da Agente Comunitária da área e de 2 alunos de Medicina, entramos na sala comum aos 11 quartos do casarão, diante das paredes sem cor definida, esburacadas, sem quadros pendurados, emoldurando os poucos móveis sujos, velhos e descuidados. Sentamos no que sobrara do sofá todo rasgado e em cadeiras e bancos espalhados pela sala. Olhava para os alunos como a pedir-lhes: percebam, sintam, atentem para uma realidade social tão diversa da de vocês. Apreendam, aprendam, reflitam...

Em poucos segundos a sala estava cheia. Todas vinham nos receber, falar de seus problemas, esclarecer dúvidas, solicitar exames, consultas, encaminhamentos, recadastramento e escuta, muita escuta. Falavam simultaneamente, com pressa, atropelando a fala umas das outras, tentando ganhar atenção exclusiva a todo custo. $\mathrm{O}$ ambiente é de furor, de explosão. Em tom alto de voz as travestis gesticulam, fazem brincadeiras umas com as outras, iniciam discussões logo amenizadas, exageram nos trejeitos femininos de se expressar. Distribuímos camisinha e gel, enviados pela Secretaria Municipal de Saúde, e, sem saber ao certo a hora de ir embora, ficamos ali, nos deixando levar pelas demandas, que certamente não eram apenas de atenção médica.

Já vai, doutora? Espera um pouco, vem aqui no meu quarto que eu tenho que te falar em particular.

De volta ao PSF, registramos nos prontuários e discutimos sobre "o vivido".

Para os alunos de Medicina, surpreende saber que as travestis têm a mesma necessidade de afeto e atenção do que qualquer pessoa e que desejam ser respeitadas como cidadãos na mesma proporção que eles, alunos. É como se, por desconhecimento e distanciamento, reconhecessem as travestis quase como "não pessoas", dotando-as de uma visão exageradamente estereotipada, fruto de estranhamentos e preconceitos.

Alguns relatos dos alunos:

"Não imaginava que elas fossem assim. São pessoas que sentem como a gente!"
"Estava com um pouco de medo de vir aqui, mas depois passou. Vi que elas não são agressivas, não tentaram me assediar, nem me roubar, sei lá, foram atélegais."

"Foi muito bom para mim conhecer elas, acho que estou menos preconceituosa, vendo elas com tantos problemas e sendo tão carentes. Vou atender elas de outro jeito agora."

"Elas têm tantas dúvidas sobre saúde, pareceram tão interessadas em tirar dúvidas. Pensava que viviam mais largadas, que não ligassem pra nada, me senti útil. Foi bom.”

Dessa forma, este trabalho tem cumprido um de seus objetivos, que é o de sensibilizar os futuros médicos e profissionais de saúde em geral no lidar com as travestis nos serviços de saúde, a partir da garantia do respeito à pessoa humana, no sentido de seu direito à saúde; além do propósito de provocar uma reflexão sobre estratégias de acolhimento de um segmento excluído da sociedade, a partir de uma ampla discussão sobre a sexualidade humana.

\section{o Acolhimento como uma Conquista}

A definição de acolhimento envolve três características fundamentais, a saber:

1. Garantia do acesso universal, ou seja, atender a todas as pessoas que procurem o serviço de saúde.

2. Reorganização do processo de trabalho, deslocando o eixo central do médico para a equipe multiprofissional de acolhimento que se encarrega de escutar o usuário na tentativa de ser resolutiva.

3. Qualificação da relação profissional de saúde-usuário, que deve dar-se de maneira humanitária, a partir da solidariedade e cidadania. (Franco e col., 1999).

0 trabalho de acolhimento realizado no PSF-Lapa com as travestis é fruto de um processo de conquista. No início enfrentamos enormes dificuldades de aceitação, talvez como reflexo da maneira preconceituosa como geralmente são tratadas nos serviços de saúde que eventualmente freqüentam, talvez como reação à exclusão social que sofrem. 0 fato é que, no começo do processo do trabalho, entrávamos em suas casas, mas elas não saiam dos quartos, oferecíamos nosso serviço 
e elas nunca compareciam, solicitávamos exames laboratoriais que não eram realizados, marcávamos consultas em vão. Durante 6 meses, essa foi uma realidade habitual. No entanto, aos poucos fomos sendo gradativamente requisitadas por elas.

Assim, este trabalho é fruto de um processo desenvolvido a partir de uma conflituosa convivência e da insistência da equipe. Certo dia, mal entrei em sua casa e uma delas gritou sem sair de seu quarto: "Doutora, trouxe camisinha?”. Estava selada nossa aproximação.

Inúmeros relatos magoados e indignados obtivemos em relação ao despreparo dos profissionais de saúde de Hospitais e ambulatórios no lidar com as travestis, tratando-as de maneira desrespeitosa, justificando absenteísmo, alta a revelia e interrupção ou abandono de tratamentos médicos.

Em 2004, o Ministério da Saúde lançou uma campanha de sensibilização dos profissionais de saúde quanto ao preconceito em relação às travestis, utilizando-se de folders, cartazes e panfletos distribuídos pelos serviços de saúde pública do país (Brasil, 2004). Na mesma época surgiu o Programa Brasil Sem Homofobia, vinculado à Secretaria Especial de Direitos Humanos da Presidência da República. Era um Programa de combate à violência e à discriminação contra GLTB (gays, lésbicas, transgêneros e bissexuais) e de promoção da cidadania homossexual, com a intenção de promover uma discussão sobre o assunto da maneira mais ampla possível (Brasil, 2004).

Ambas as iniciativas, embora tenham causado certo impacto pelo seu ineditismo, não mantiveram um compromisso com a continuidade, prejudicando assim, sua amplitude de eficácia junto ao SUS.

No entanto, conseguimos, no decorrer destes seis anos, realizar cuidados médicos, odontológicos, de enfermagem, fisioterápicos, nutricionais e fonoaudiólogos com a maioria das travestis adscritas, melhorando sua auto-estima e sua qualidade de vida, mas, principalmente, garantindo um acesso como porta de entrada no sistema de saúde.

\section{A Visita Domiciliar como Estratégia}

A visita domiciliar na estratégia Saúde da Família serve a diversos propósitos: consultas; cadastramento da população; recadastramento; busca ativa na tentativa de resolução de casos de abandono de tratamento; rea- lização de vigilância à saúde ou vigilância epidemiológica; entrega de convites de atividades de educação em saúde, de reuniões comunitárias. Enfim, é uma estratégia de diálogo com a comunidade, de aproximação e de refinamento da relação estabelecida com toda a equipe de trabalho.

No caso das travestis, a visita domiciliar tem sido utilizada principalmente como estratégia de captação e acolhimento, em consonância com a proposta de um trabalho voltado para as necessidades de saúde das pessoas, promovendo, assim, o estabelecimento e manutenção do vínculo entre os profissionais da equipe, os alunos e as travestis.

Como já relatado no início do trabalho, além de não saírem de seus quartos, elas não compareciam de maneira alguma ao ambulatório e, percebendo a diversidade de problemas e questões a serem explorados pelo trabalho em equipe proposto, começamos a nos utilizar, com uma freqüência sistemática, semanal, das visitas domiciliares como estratégia de aproximação. Desta forma, íamos aos poucos nos conhecendo, nos apresentando, reforçando a intenção do trabalho.

Eventualmente era convidada a entrar no quarto de uma delas onde permanecia por até 1 hora ouvindo confidências, desabafos e suas histórias de vida. Outras vezes, elas juntavam-se em grupos de 4 ou 5 em um dos quartos e estabelecíamos uma conversa coletiva, só interrompida pelo avançar da hora. Ríamos muito também; o bom humor é quase como um pacto de convivência.

Passei a perceber que não necessitava mais de uma consulta formal com elas no ambiente ambulatorial, realizando ali, no casarão, exame físico, diagnóstico e tratamento, dependendo da situação. No entanto, algumas necessitavam de pequenos procedimentos, de um controle da pressão arterial, do peso, ou mesmo não se sentiam à vontade de falar de si e de seus problemas de saúde em sua moradia.

Apesar de o trabalho ser de equipe, começaram a me solicitar no ambulatório, sempre como demanda espontânea, sem marcação prévia de consulta. Chegavam freqüentemente em duplas ou trincas, geralmente no fim da manhã ou no fim da tarde. Sempre me procuravam como referência, mesmo que fosse para a resolução de problemas que necessariamente envolvessem outro profissional de saúde da equipe. Fui consolidando um espaço, conquistando um lugar para as traves- 
tis não apenas no PSF-Lapa, mas no sistema local de saúde, já que muitas vezes precisava encaminhá-las para outro nível de complexidade da atenção.

\section{A Recepção das Travestis pela Equipe de Saúde}

Logo que começaram a comparecer na nossa Unidade de Saúde, algumas esperadas reações dos profissionais da equipe surgiram: expressões de surpresa, algumas vezes de condenação, comentários sobre suas roupas, seus modos de andar, sua atitude na sala de espera, seu jeito de falar, sua aparência, seus trejeitos mais ou menos parecidos com os de uma mulher, seu corpo sempre a mostra. Ia ouvindo cada um que vinha tecer algum comentário comigo e freqüentemente tentava anular o tom jocoso que traziam, respondendo com firmeza, mas docemente, sobre a importância da presença delas no ambulatório, a partir da reafirmação do direito à saúde de todos, sem exceção.

Durante algum tempo passei a ser foco de citações da equipe que se referia a mim como "a doutora das travestis", "chegaram suas amiguinhas", "ela gosta disso..."

No entanto, aos poucos toda a equipe foi entendendo a dimensão do trabalho, passando a respeitá-lo. Hoje as travestis, sempre chamadas pelo nome que desejam e não pelo nome da identidade, têm um lugar estabelecido na Unidade.

No início elas não se sentavam, queriam atendimento imediato, ficavam em pé ao lado da porta de meu consultório e, na primeira oportunidade, me seguravam pelo braço pedindo: "Me atende logo...", falavam alto, gesticulavam exageradamente, como reação ao estranhamento mútuo que se estabelecia na sala de espera com as pessoas que aguardavam atendimento.

Começamos a colocar cartazes de divulgação sobre preconceito e profissionais de saúde na sala de espera, discutir com a comunidade sobre sexualidade, organizar sessões de cinema com filmes que promovessem uma discussão sobre diversidade.

Hoje as travestis do PSF-Lapa se sentam com calma, esperam sua vez para atendimento, interagem com as pessoas a sua volta na sala de espera. Apropriaramse de seu lugar, de seu espaço, de seu direito de estar ali como qualquer outra pessoa.
O estranhamento da comunidade diminuiu. A equipe humanizou-se na relação profissional de saúde-usuário, deixando de estigmatizar e nutrir preconceitos. Quando chego, ouço os relatos: "olha ontem atendi ela, dei a injeção, deu tudo certo", "elas estavam lindas, precisava ver..."

Aceitando meu trabalho como educativo e sendo a educação um processo que prescinde do fator tempo para se consolidar (Perrenoud, 1999), acredito estar promovendo um processo de inclusão, que vem sendo delineado por uma discussão sobre sexualidade em geral, identidade e orientação sexual, em particular no contexto de uma Unidade de saúde-escola de um grande centro urbano.

\section{Considerações Finais}

A intenção desse artigo foi, antes de tudo, propiciar um encontro que renovasse a percepção sobre uma realidade social específica, ampliando, assim, a compreensão geral de fenômenos humanos. Relata uma experiência consolidada de acolhimento, construída a partir do parâmetro da universalidade, integralidade e eqüidade na busca do SUS que desejamos.

Ao utilizar ações educativas específicas diante do desafio da inclusão das travestis no cotidiano de um serviço de atenção básica, na verdade propõe-se produzir saúde a partir da luta pelo direito à dignidade, em um seguimento possuidor de vulnerabilidade social, exposto à exclusão, violência, preconceito e discriminação. Todos somos iguais, enquanto seres humanos, todos temos direito à saúde perante as leis brasileiras, todos merecemos ser tratados com respeito, independente do conceito de normalidade atribuído (Canguilhen, 1995).

Assim, estratégias diferenciadas de acolhimento devem ser implementadas no lidar com diversidades, incentivando a promoção de ações e práticas a partir do estabelecimento de uma rede de cuidados (Pinheiro e Mattos, 2001).

A grande questão que o artigo supõe, considerando a estratégia Saúde da Família, é que somente através do diálogo, estabelecido entre profissionais de saúde e usuários, poderemos produzir transformações nas práticas de saúde.

Em relação às travestis do PSF-Lapa, as alternativas específicas de acolhimento encontradas foram: a 
adoção do livre atendimento, garantindo acesso imediato às consultas, utilizando-se, no entanto, de agendamento prévio principalmente nas situações de necessidade de acompanhamento sistemático e contínuo da atenção; como para seguimento de tratamento ou procedimento, a exemplo de consultas de fisioterapia, odontologia, fonoaudiologia e encaminhamentos para especialistas.

Propomos que as travestis sejam tratadas pelo artigo feminino, oralmente e por escrito nos prontuários, tomando apenas o cuidado de também registrar os dados que constam em seus documentos de identidade.

Pactuar com os gestores locais, garantindo o atendimento para outros níveis de complexidade do sistema de saúde, é um direito que não se distingue do de qualquer cidadão; no entanto, para as travestis, permite um fluxo próprio que favorece sobremaneira a adesão ao tratamento.

Distribuir ininterruptamente camisinha e gel em quantidades suficientes para manutenção do trabalho como profissionais do sexo, valoriza a realização de sexo seguro.

Estabelecer o maior nível local de resolubilidade possível, não ter preconceito nem utilizar-se de discurso moralista que apenas reforça uma relação de poder (Bourdieu, 2006), dificultando o trabalho na direção da redução de danos, passou a ser uma prioridade.

Redução de danos é aqui entendida como uma política social que tem o papel de discutir e incentivar ações científicas e sociais que terão, a médio e longo prazo e de maneira prática -, a função de trabalhar - diretamente, para que os usuários de todas as drogas possam usá-las, em respeito ao cidadão e à liberdade de escolha, da maneira menos danosa possível (Reduc, 2007).

Divulgar para a comunidade em geral a dimensão do trabalho realizado com as travestis por meio de dinâmicas e cartazes colocados na sala de espera e discutidos durante atividades de promoção da saúde, despertam o interesse em pensar sobre o assunto, prevenindo o preconceito e a discriminação.

Em relação aos estudantes, o grande ganho foi a familiaridade que passaram a ter com a realidade de vida das travestis, resultando em uma postura humanizada a partir de um olhar ampliado sobre o processo saúde-doença-cuidado.
A preocupação em implementar políticas de saúde que contemplem as necessidades específicas das travestis, a exemplo da aplicação de silicone industrial e ingestão excessiva de hormônios femininos, além do uso abusivo de drogas lícitas e ilícitas, é apostar no respeito à diferença e na valorização da dignidade humana.

O direito à saúde deve ser uma prioridade universal, dentro de um SUS que ajudamos a construir, no cotidiano dos serviços que são formados por pessoas, as únicas que podem, de fato, transformar a realidade.

\section{Referências}

BRASIL. Conselho Nacional de Combate à Discriminação. Brasil sem homofobia: programa de combate à violência e a discriminação contra GLTB e promoção da cidadania homossexual. Brasília, DF: Ministério da Saúde, 2004.

BRASIL. Ministério da Saúde. Secretaria de Atenção à Saúde. Departamento de Atenção Básica. Política Nacional de Atenção Básica. Brasília, DF, 2006.

BOURDIEU, P. O poder simbólico. 9. ed. Rio de Janeiro: Bertrand Brasil, 2006.

CANGUILHEN, G. O normal e o patológico. Rio de Janeiro: Forense Universitária, 1995

CFP - CONSELHO FEDERAL DE PSICOLOGIA. Disponível em: <www.cfp.org.br $>$. Acesso em: 10 fev.2006.

\section{CENTRO COLABORADOR DA OMS PARAA} CLASSIFICAÇÃO DE DOENÇAS. CID-1o - Classificação Estatística Internacional de Doenças e Problemas relacionados à Saúde. 10. rev. São Paulo, 1993. v. 1. Disponível em: <www.datasus.gov.br/cidio/webhelp/ cidio.htm> Acesso em: 2 fev. 2007.

FACCHINI, L. A. et al. Desempenho do PSF no Sul e no Nordeste do Brasil: avaliação institucional e epidemiológica da atenção básica à Saúde. Revista Brasileira Saúde da Família, Brasília, DF, ano VIII, n. 13, jan./mar. 2007. 
FRANCO, T. B.; BUENO, W. S.; MERHY, E. E.. 'User embracement' and the working process in health: Betim's case, Minas Gerais, Brazil. Cadernos de Saúde Pública, Rio de Janeiro, v. 15, n. 2, 1999.

Disponível em: <http://www.scielo.br/ scielo.php?script=sci_artext\&pid=80102 $>$. Acesso em: 25 mar. 2007.

GOFFMANN, E. A representação do eu na vida cotidiana. Petrópolis: Vozes, 1975.
PERRENOUD, P. Construindo as competências desde a escola. Porto Alegre: ArtMed, 1999.

PINHEIRO, R.; MATTOS, R. A. (Org.). Os sentidos da integralidade na atenção e no cuidado à saúde. Rio de Janeiro: UERJ, IMS: ABRASCO, 2001.

REDUC - REDE NACIONAL DE REDUÇÃO DE DANOS. Disponível em: <www.reduc.org.br>. Acesso em: 1 mar. 2007. 